\title{
Human-Structure Dynamic Interaction during Short-Distance Free Falls
}

\author{
E. Shahabpoor ${ }^{1}$ and A. Pavic ${ }^{2}$ \\ ${ }^{1}$ INSIGNEO Institute for In-Silico Medicine, The University of Sheffield, Department of Civil \& Structural Engineering, \\ Sir Frederick Mappin Building, Mappin Street, Sheffield S1 3JD, UK \\ ${ }^{2}$ Vibration Engineering Section, College of Engineering, Mathematics and Physical Sciences, University of Exeter, \\ North Park Road, Exeter EX4 4QF, UK
}

Correspondence should be addressed to E. Shahabpoor; e.shahabpoor@sheffield.ac.uk

Received 7 June 2016; Accepted 15 August 2016

Academic Editor: Yuri S. Karinski

Copyright (C) 2016 E. Shahabpoor and A. Pavic. This is an open access article distributed under the Creative Commons Attribution License, which permits unrestricted use, distribution, and reproduction in any medium, provided the original work is properly cited.

The dynamic interactions of falling human bodies with civil structures, regardless of their potentially critical effects, have sparsely been researched in contact biomechanics. The physical contact models suggested in the existing literature, particularly for shortdistant falls in home settings, assume the human body falls on a "rigid" (not vibrating) ground. A similar assumption is usually made during laboratory-based fall tests, including force platforms. Based on observations from a set of pediatric head-first free fall tests, the present paper shows that the dynamics of the grounded force plate are not always negligible when doing fall test in a laboratory setting. By using a similar analogy for lightweight floor structures, it is shown that ignoring the dynamics of floors in the contact model can result in an up to $35 \%$ overestimation of the peak force experienced by a falling human. A nonlinear contact model is suggested, featuring an agent-based modelling approach, where the dynamics of the falling human and the impact object (force plate or a floor structure here) are each modelled using a single-degree-of-freedom model to simulate their dynamic interactions. The findings of this research can have wide applications in areas such as impact biomechanics and sports science.

\section{Introduction}

An impact force is usually characterized by high frequency content, short duration, and a high peak magnitude. These characteristics are highly dependent on several factors, such as the energy dissipation mechanism during the impact, time varying geometry of the contacting surfaces, and material properties which are often nonlinear [1]. These factors make it very challenging to model an impact on a complex mechanical system such as a human body. Modelling the viscoelastic response of the human body to impacts using simple mechanical models [2-7] and the attenuation of the corresponding forces as they are transmitted through the body [8-16] are well documented in the literature. However, the dynamic interaction of the human body with environment (referred to as impact "object" in this paper not to be confused with the human "body") is often neglected in contact models. In the context of this paper, interaction refers to the mutual dynamic effects of two or more degrees of freedom (DoFs) in a mechanical system on one another.

Neglecting the effects of interaction is often based on the assumption that the impacting object is rigid and not vibrating and, therefore, no interaction happens. Such assumption is commonly used for modelling short-distant free falls, where the impacting object (usually the ground) is assumed to be rigid (not vibrating). However, in reality a considerable number of these falls happen on lightweight building floors, such as composite and timber floors, or on raised (also known as false) floors. These floor structures are usually characterized by low mass and damping ratio and, therefore, can be excited by the body impact force. Consequently, their dynamics have the potential to change the impact force and may need to be considered in the contact model. An example of such dynamic effects in the case of walking pedestrians is presented by Shahabpoor et al. [17], which reveals that 
human-structure dynamic interaction can affect structural response significantly and is not always negligible.

Similar to falls on floor structure, interaction effects are commonly assumed negligible when measuring human fall force in the laboratory environment using grounded force plate (fixed support). The dynamics of the force plate are usually ignored in contact models, as these are considered beyond the range excitable by human fall impact force.

The present paper investigates the interaction of the falling human body with the impacting object and demonstrates the following:

(1) The interaction of the falling human body and a grounded force plate, as the standard tool for fall force measurement [18-20] in laboratory, can be considerable and, therefore, needs to be taken into account in contact models. These interactions are due to the dynamics of the force plate itself and happens regardless of the fact that force plate is securely fixed to a rigid ground or support.

(2) In real-world indoor falls, depending on the dynamic properties of the floor/raised floor, there can be a significant interaction between the falling human and the structure. Therefore, the dynamics of the floor structure need to be considered in the contact model.

The paper further suggests a simple and practical methodology to model these dynamic interaction effects and explores the effects of considering the more realistic nonlinear behavior of human body parameters during impact [21-26]. The effect of structural vibrations on the force plate measurements is, however, beyond the scope of this research and was not studied here.

Section 2 of the paper describes a set of pediatric headfirst free fall tests carried out to measure the interaction effects between a falling human and a grounded force plate. The proposed contact model is described in Section 3. The identification procedure used to find the unknown parameters of this contact model (for both linear and nonlinear human body models) is described in Section 4. Section 5 extends the observations made in Section 2 and explores parametrically the effects of the dynamics of building floors and raised flooring systems on peak impact force experienced by a falling human (no force plate). Finally, the conclusions are highlighted in Section 6.

The suggested contact model can be particularly useful in modelling more realistically the pediatric falls from bed and other household items. Such falls which are a common cause of injury in children are sometimes used to conceal child abuse [27-38]. Another notable application is for modelling elderly falls, where relating the fall scenario with potential injuries can be extremely useful from both treatment and prevention perspectives. In both cases, when falls happen on a lightweight floor or raised floor, as is shown in Section 5, the actual impact force experienced by the falling human can be considerably less compared to falling on a rigid floor. Therefore the contact model suggested in this paper can provide more realistic contact force values by considering the dynamics of the floor/raised floor.

\section{Experiments}

The short-distance free fall of a child is selected as the impact scenario for experiments due to its importance, the simplicity of the fall mechanism, and the absence of fall arrest reflexes. As to the other scenarios and participants, the choice of the impact scenario selected here does not affect the generality of the proposed methodology. However, the contact model used needs to be adapted to other scenarios to best simulate the dynamics of the impacting bodies.

A set of experiments were carried out, in which a scaled infant dummy was released from five initial heights of $0.3 \mathrm{~m}$ (T01), $0.5 \mathrm{~m}$ (T02), $0.7 \mathrm{~m}$ (T03), $0.9 \mathrm{~m}$ (T04), and $1.1 \mathrm{~m}$ (T05) to fall freely on a grounded force plate (AMTI model BP400600) in a vertical head-first position. The $0.5 \mathrm{~m}$ height represents a typical height of a bed, while $0.9 \mathrm{~m}$ represents a high table or a counter. The initial heights were measured between the top of the dummy head and the force plate surface. The fall tests T02 $(0.5 \mathrm{~m})$ and T04 $(0.9 \mathrm{~m})$ were each repeated 50 times to assess the repeatability of the results.

An infant dummy, developed by the authors, was used in the experiments with the scaled-down total mass of $0.35 \mathrm{~kg}$ to protect the force plate sensors from overload during the tests. The dummy had realistic dimensions corresponding to a 6week infant [36] and its mass was anthropometrically scaled and distributed between body segments. The mechanical parameters of the joints and head were not known. The latter, however, deemed not to reduce the generality of the observations presented in this paper. This is because the key aim of this research is to show that the dynamic interactions between the falling human body and the impacting object can be significant and are not always negligible.

The impact forces transmitted to the rigid ground were recorded using the force plate, with a maximum possible sampling frequency of $1,000 \mathrm{~Hz}$ [39]. The force plate was tightly fixed to the building reinforced concrete foundation using four bolts.

A VICON optical motion capture system [40] was used to record the kinematics of the dummy fall, with a sampling frequency of $100 \mathrm{~Hz}$. In total, 10 markers, attached to the feet, pelvis, hands, shoulders, and head, were used to capture the 3D displacement of the dummy. These displacement data were used to calculate the deviation of the head-torso center line from vertical axis (earth reference frame) at the point of impact. Only the experiments that the angle of impact had less than 5 degrees of deviation from the vertical axis were used for analysis. Moreover, the experiments where a limb/s also impacted the force plate within the $30 \mathrm{~ms}$ time-window of the head impact were excluded from the analysis.

In these experiments the dummy and the force plate are the impacting objects and their dynamic interaction is analyzed using the impact force measured by the force plate. Figure 1 shows a typical time history of such impact force.

The force "ringing" (after point (D)) after the main impulse peak (between points (A) and (D)) is an indication of the significant contribution of the force plate dynamics during the impact to the total measured impact force. This confirms that, to find the actual impact force applied on the dummy, the dynamics of the force plate need to be taken into 


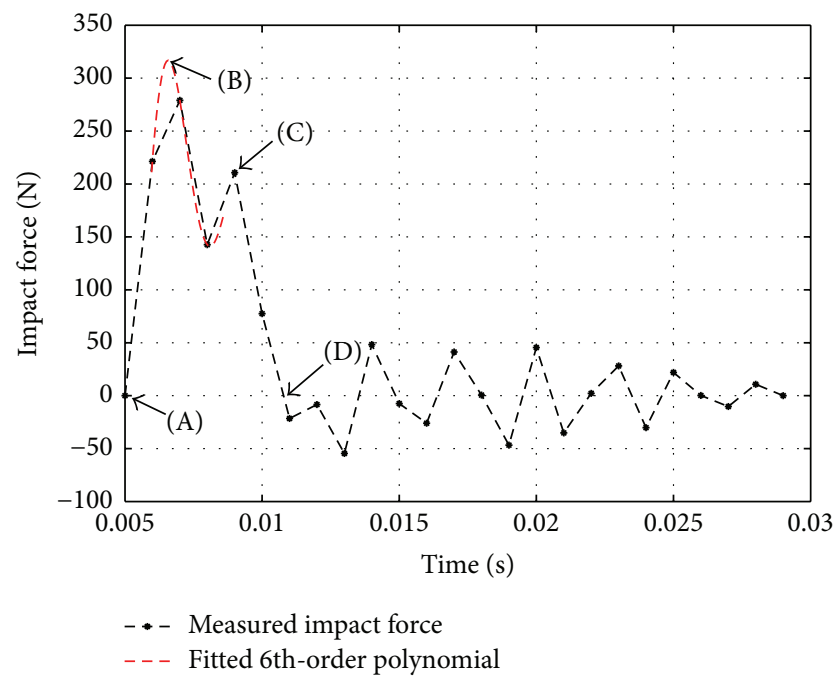

FIgURE 1: A typical experimentally measured time history of the impact force and the corresponding fitted 6th-order polynomial. The points in time representing the start of the impact $(A)$, the maximum deformation (B), the secondary peak (C), and the end of restitution phase (D) are shown on the figure.

account via a model, simulating better the contact between the dummy and the force plate.

Three phases can be identified in the impact force signal shown in Figure 1: compression ((A)-(B)), restitution ((B)$(D)$ ), and the force plate oscillation (after $(D))$. The first two phases are standard in noninteractive impacts [1, 41-44]. The compression phase begins when the two bodies come into contact (point (A)) and finishes when the combined maximum deformation is reached (point (B)). The restitution phase begins at point $(B)$ and finishes when the overall effect of the two bodies starts putting the force sensor(s) in tension (point (D)). The signal after point (D) is dominated by the oscillation of the force plate top plate (while the dummy is flying upwards), which results in the exchange of negative (tension) and positive (compression) force magnitudes recorded after point $(D)$.

The resolution of the measured force signal in Figure 1 indicates that a maximum sampling frequency of $1,000 \mathrm{~Hz}$ is not high enough to fully capture the impact force signal. To compensate for this problem, a sixth-order polynomial was empirically fitted to the measured impulse curve maxima to estimate the peak impact force $F_{i, \max }$ magnitude (Figure 1, dashed curve). The peak impact force values estimated using these fitted polynomials (point (B)) are presented in Table 1 and were used in the identification process described in Section 4.

Figure 2 shows the envelope of the 50 measured impact forces for tests T02 (a) and T04 (b). The difference between measured forces for each height is partially attributed to the slight difference in the posture of the dummy at the time of impact and the movements of the limbs during impact. For each of T02 and T04 sets of tests, first, the average impact force was calculated by averaging the 50 force signals in time. Then, the measured force signal (out of the 50 measured signals) with the least square error compared to this average
TABLE 1: Peak magnitude of the measured impact forces.

\begin{tabular}{ccc}
\hline Test & Fall height $(\mathrm{m})$ & $F_{i, \max }(\mathrm{N})^{*}$ \\
\hline T01 & 0.3 & 242.3 \\
T02 & 0.5 & 321.4 \\
T03 & 0.7 & 400.1 \\
T04 & 0.9 & 451.8 \\
T05 & 1.1 & 500.4 \\
\hline
\end{tabular}

${ }^{*}$ The peak force magnitudes are estimated from the fitted polynomial curves.

impact force was selected to represent the corresponding fall height. These representative measured force signals are shown in Figure 2 with dashed curves.

\section{Contact Model}

As is defined in Section 1, interaction in this paper refers to the mutual dynamic effects of two or more independently moving DoFs in a mechanical system on one another. Based on this definition, the mere taking into account the stiffness and/or damping of the impacting surface (e.g., due to falling on a carpet) is not considered interaction here. Moreover, the focus of the proposed contact model in this study is more on the dynamics of the impact, rather than contact mechanics. The latter traditionally aims to solve problems of stress and displacement distributions in the contact surfaces during an impact, as well as the propagation of the impact wave through the impacting objects. However, here, we are interested in peak impact forces acting on a falling body.

3.1. Human and Impact Object Models. A single-degree-offreedom (SDOF) mass-spring-damper (MSD) mechanical model was used to simulate the dynamics of the force plate (Figure 3). The natural frequency $(370 \mathrm{~Hz}$ ) and damping ratio $(1 \%)$ of the force plate SDOF model were adopted from its manufacturer's data-sheet [39] and its mass $m_{\mathrm{fp}}$ was taken as the mass of its top aluminum plate $(\sim 15 \mathrm{~kg})$. This SDOF model represents the vibration of the force plate top plate, sitting on the force sensors with total stiffness $k_{\mathrm{fp}}$ and damping $c_{\mathrm{fp}}$. The sensors are assumed to be connected to a rigid base. To make sure this is a realistic assumption, during experiments, the base of the force plate was fixed to the building reinforced concrete foundation using four bolts.

Similarly, a SDOF MSD model was used to simulate the dynamics of the child body. The SDOF model is a reasonably realistic first estimation for pediatric head-first vertical free falls, due to the simplicity of the fall mechanism and absence of fall arrest reflexes. The mass of the human model must represent the part of the body that contributes to the impact force and is dependent on the fall mechanism, body posture, and the contact point during impact. All of the child SDOF model parameters were treated as unknowns in this study and were found via the system identification procedure described in Section 4.

A number of assumptions were used in the model to simplify the analysis. The impact between the force plate and the child dummy was assumed to be collinear, where the 


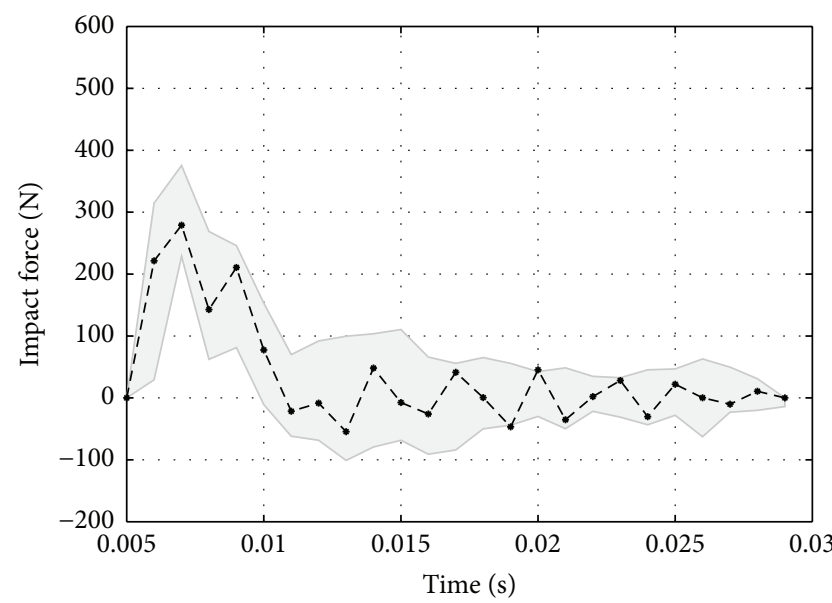

Envelope of measured forces - - Representative measured force

(a) T02: $0.5 \mathrm{~m}$

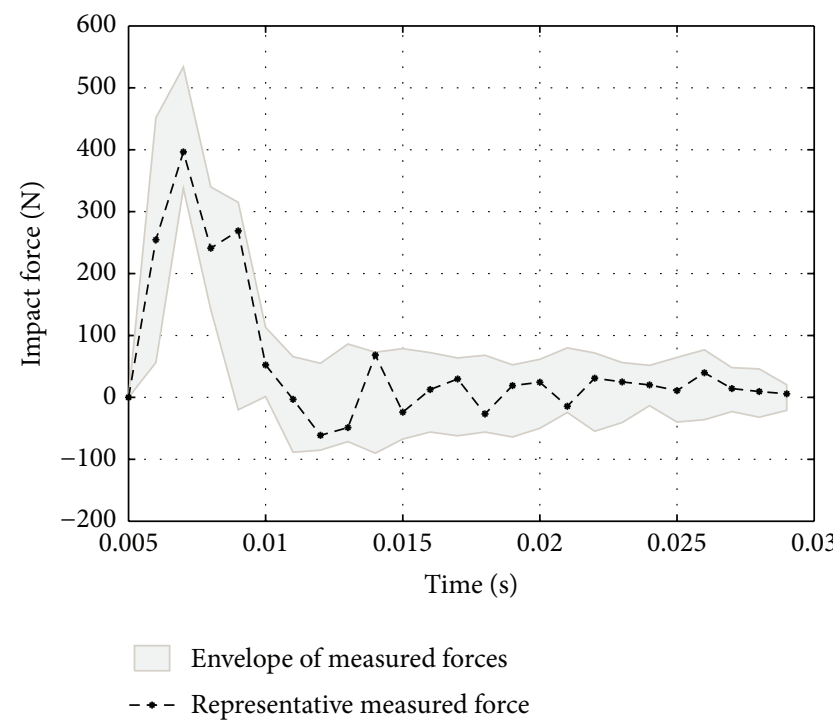

(b) T04: $0.9 \mathrm{~m}$

FIgURE 2: Envelope of the 50 measured impact forces.

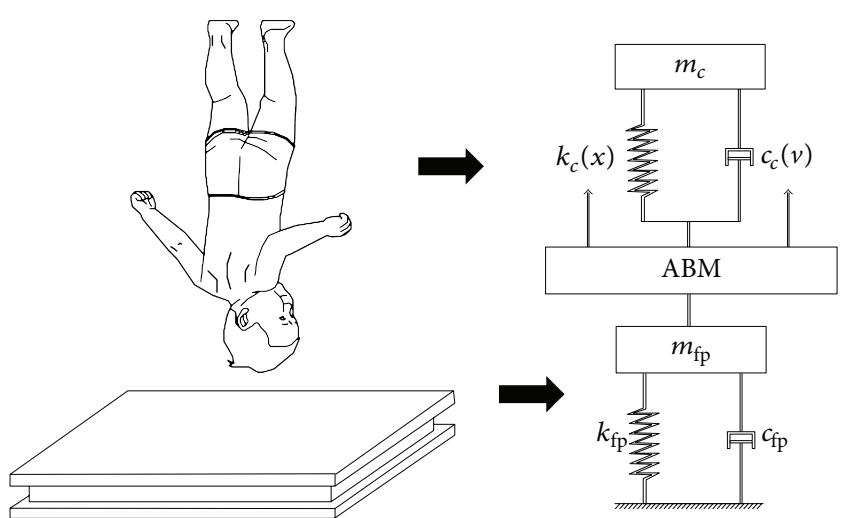

Figure 3: The schematic of the child-force plate model featuring agent-based model (ABM) at the interface between the body and force plate.

mass centers of the two bodies are on the line of impact; direct, where the initial velocities of the two bodies are along the line of impact; unidirectional, only in the vertical direction; frictionless and partially elastic, with energy loss but no permanent deformation. It was further assumed that the deformation was concentrated in the vicinity of the contact area, elastic wave motion was neglected, and the total mass of each body moved with the velocity of its center of mass.

A body falling freely through the air under the effect of gravity will experience an opposing force due to air resistance. However, this resisting force is shown to be insignificant for fall heights of less than $15 \mathrm{~m}[45,46]$. Assuming linear acceleration and neglecting air resistance, the vertical velocity " $v$ " at the beginning of impact can be calculated using the following well-known formula:

$$
v=\sqrt{2 g h}
$$

where " $h$ " is the initial height of the fall and " $g$ " is the gravitational acceleration. The velocity " $v$ " was calculated for each fall height and was used as the initial condition in the contact model shown in Figure 3 (right) to initiate the impact simulation.

Several studies have shown that the human body (tissues and bones) exhibits high levels of nonlinearity and interand intrasubject variability in its mechanical parameters [2126, 47, 48]. For instance, Mohan et al. [47] suggested a bilinear model of stiffness for the human head, based on the study of head-first free falls of 30 children. Inspired by such observations, two types of child models were compared in this study:

(i) A linear model, the parameters of which $\left(k_{c}\right.$ and $\left.c_{c}\right)$ were constant.

(ii) A nonlinear (bilinear) model, the stiffness $\left(k_{1 c}\right.$ and $\left.k_{2 c}\right)$ and damping $\left(c_{1 c}\right.$ and $\left.c_{2 c}\right)$ of which were displacement and velocity dependent, respectively (Figure 4).

In Figure $4, x$ and $v$ are the displacement and velocity values, where the stiffness and damping of the bilinear (denoted with "bl") child (denoted with " $c$ ") model change from $k_{1 c}$ to $k_{2 c}$ and from $c_{1 c}$ to $c_{2 c}$, respectively.

3.2. Interaction Simulation. An agent-based model (ABM) was used to simulate the interaction of the falling child and the force plate. An ABM, sometimes called an individualbased model, is a class of computational micro scale models [49] for simulating the actions and interactions of autonomous "agents" to assess the overall system behavior. Agents are the smallest elements of the system that interact with other parts of the system. Conceptually, ABM defines the behavior of agents at the micro level, and the macro behavior of the system emerges from all the interactions 


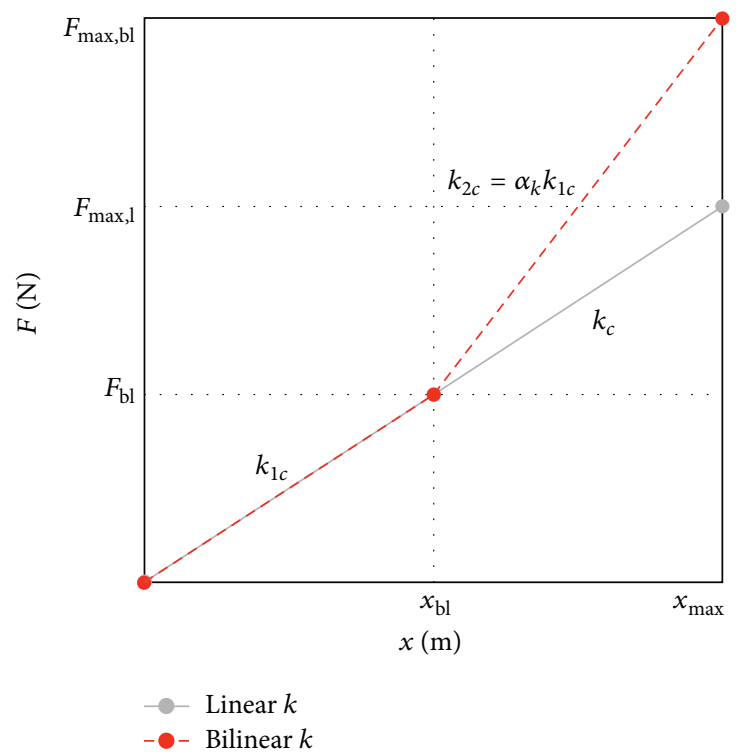

(a) Child model stiffness

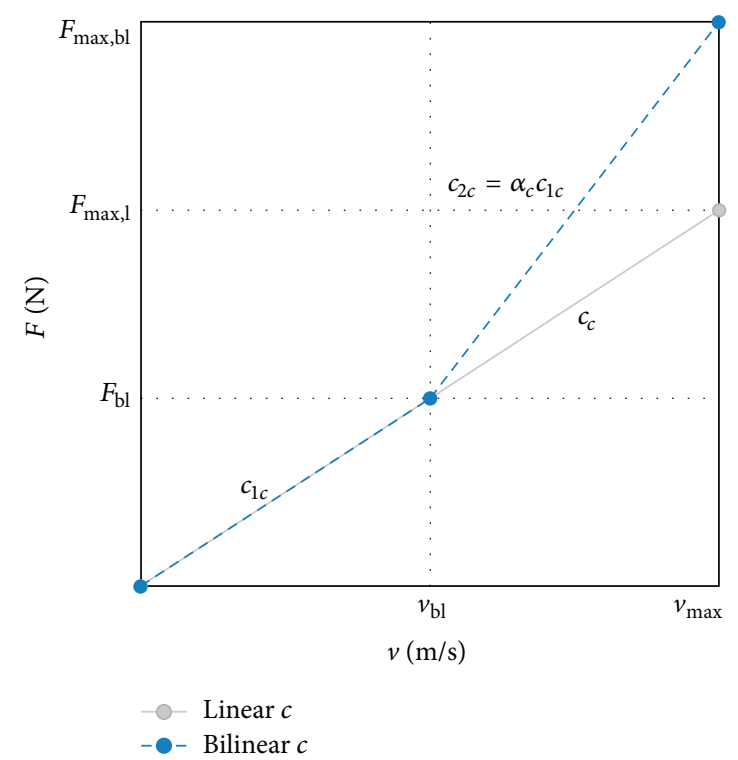

(b) Child model damping

Figure 4: The stiffness (a) and damping (b) of the child model.

between entities [50]. This architecture allows agents to perceive their "environment" and provides them with initiative, independence, and ability to interact with other agents [51].

The child and force plate SDOF models were each modelled as an agent, the interactions of which were regulated by the ABM (Figure 3). The Newmark average acceleration method [52] was used to simulate numerically the response of each SDOF model. The discontinuity of the falling child and the force plate was taken into account to avoid the generation of tensional force between the child and the force plate. In each time step of the simulation, the following sequence takes place.

(I) Set the next time step " $i$ ":

$$
t_{i}=t_{i-1}+d t
$$

where $d t$ is the simulation time step.

(II) It is determined whether the child dummy and force plate are in contact by checking the relative displacement between child and force plate degrees of freedom. If the relative displacement is greater than spring length at rest, that is, spring in tension, the child and force plate are considered not to be in contact:

$$
\begin{aligned}
& \text { if }\left|x_{c}\left(t_{i-1}\right)-x_{f}\left(t_{i-1}\right)\right|>x_{s, \text { rest }} \longrightarrow \text { not in contact, } \\
& \text { if }\left|x_{c}\left(t_{i-1}\right)-x_{f}\left(t_{i-1}\right)\right|<x_{s, \text { rest }} \longrightarrow \text { in contact. }
\end{aligned}
$$

(III) If the child and force plate are connected, the displacement $x_{f}\left(t_{i-1}\right)$ and velocity $\dot{x}_{f}\left(t_{i-1}\right)$ responses of the force plate (agent) SDOF model (from the previous time step) are transmitted to the child (agent) SDOF model as base excitation. Otherwise, the base excitation carried from the force plate to the child is set to zero and only the gravitational force is applied on the child's mass:

$$
\begin{aligned}
& m_{c}\left(\ddot{x}_{f}-\ddot{x}_{c}\right)+c_{c}\left(\dot{x}_{f}-\dot{x}_{c}\right)+k_{c}\left(x_{f}-x_{c}\right) \\
& =m_{c}\left(\ddot{x}_{f}+g\right) .
\end{aligned}
$$

(IV) Set the values of stiffness and damping of the child model.

(a) For the nonlinear model:

(i) the values of the stiffness (displacement dependent) and damping (velocity dependent) of the child (agent) SDOF model are calculated for this time step using the absolute values of the relative displacement $\left(\left|x_{c}\left(t_{i-1}\right)-x_{f}\left(t_{i-1}\right)\right|\right)$ and velocity $\left(\mid \dot{x}_{c}\left(t_{i-1}\right)-\right.$ $\left.\dot{x}_{f}\left(t_{i-1}\right) \mid\right)$ in the previous time step;

(ii) if the child and force plate are not connected, these values are set to zero for the current time step.

(b) For the linear child dummy model: if the child and force plate are not connected, the stiffness and damping of the child model are set to zero for the current time step.

(V) The displacement, velocity, and acceleration responses of the child (agent) SDOF model to the combined effects of its base excitation and the gravitational force were calculated by taking into account its displacement and velocity in the previous time step as the initial conditions for the current step. The Newmark method was used for the response calculation. 
(VI) It is determined whether the child dummy and force plate are in contact:

$$
\begin{aligned}
& \text { if }\left|x_{c}\left(t_{i}\right)-x_{f}\left(t_{i-1}\right)\right|>x_{s, \text { rest }} \longrightarrow \text { not in contact, } \\
& \text { if }\left|x_{c}\left(t_{i}\right)-x_{f}\left(t_{i-1}\right)\right|<x_{s, \text { rest }} \longrightarrow \text { in contact. }
\end{aligned}
$$

(VII) If the child and force plate are attached/in contact, the acceleration response of the child (agent) SDOF model is transmitted to the force plate (agent) SDOF model in the form of external force. Otherwise, the force transmitted to the force plate is set to zero:

$m_{f}\left(\ddot{x}_{f}\right)+c_{f}\left(\dot{x}_{f}\right)+k_{f}\left(x_{f}\right)=m_{c}\left(\ddot{x}_{c}\right)+m_{f} g$.

(VIII) The response of the force plate (agent) SDOF model (displacement, velocity, and acceleration) to the external force was calculated by taking into account its displacement and velocity in the previous time step as the initial condition for the current step. The Newmark method was used for the response calculation.

(IX) The process was repeated, starting from "(I)" until the last time step of the simulation.

The impact force experienced by the child during impact was calculated using $m_{c} \ddot{x}_{c}(t)$. Similarly, the impact force measured by the force plate is calculated using $m_{c} \ddot{x}_{c}(t)+$ $m_{f} \ddot{x}_{f}(t)$.

\section{Identification Procedure}

Most of the contact models suggested in the literature for the simulation of human falls were identified in a way to best predict the peak impact force exerted on the human subject. The identification procedure in this study, however, is focused on the overall dynamics of the child-force plate system. It uses an iterative optimization approach to identify the unknown parameters of the child model in a way to get the best match between the impact force time history estimated using the contact model and its corresponding experimental counterpart.

The cost function (CF in (7)) of the optimization process was defined as the residual sum of squares (RSS) of the differences between the analytical $F_{f \text {,ana }}\left(t_{i}\right)$ and experimental $F_{f \text {,exp }}\left(t_{i}\right)$ values of the impact force at force plate DoF during the first $0.01 \mathrm{~s}$ of the impact (Figure 1, between $0.005 \mathrm{~s}$ and $0.015 \mathrm{~s}$ ). This included the first positive half oscillation (Figures 1(A)-1(D)) representing the contribution of both the child and the force plate and the part between (D) and $0.015 \mathrm{~s}$ which predominantly represents the force plate dynamics:

$$
\mathrm{CF}=\sum_{i=1}^{10}\left(F_{f, \exp }\left(t_{i}\right)-F_{f \text {,ana }}\left(t_{i}\right)\right)^{2} .
$$

Test T02 was used to identify the parameters of the child model and tests T01, T03, T04, and T05 were used for validation. For the linear child model, the initial ranges of $25 \%-100 \%$ of dummy mass for mass $\left(m_{c}\right), 5 \mathrm{~Hz}-200 \mathrm{~Hz}$ natural frequency $\left(f_{c}\right)$, and $1 \%-70 \%$ damping ratio $\left(\zeta_{c}\right)$ were considered in the optimization process, which aimed to minimize the cost function. The initial ranges of the parameters considered for the bilinear child model were $0.25 m_{c}<m_{1 c}<1.0 m_{c}, 5 \mathrm{~Hz}<f_{1 c}<200 \mathrm{~Hz}, 1 \%<\zeta_{1 c}<$ $70 \%, 0.25 x_{\max }<x_{\mathrm{bl}}<0.75 x_{\max }, 0.25 \dot{x}_{\max }<\dot{x}_{\mathrm{bl}}<0.75 \dot{x}_{\text {max }}$, $0.25<\alpha_{k}=k_{2 c} / k_{1 c}<5.0$, and $0.25<\alpha_{c}=c_{2 c} / c_{1 c}<5.0$, where $x_{\mathrm{bl}}, \dot{x}_{\mathrm{bl}}, x_{\max }$, and $\dot{x}_{\max }$ (denoted with " $v$ ") are defined in Figure 4. The ABM described in Section 3.2 was used to simulate each test and to calculate the impact force time history. The simulation was performed for all combinations of $m_{c}, f_{c}$, and $\zeta_{c}$ for the linear model and $m_{1 c}, f_{1 c}, \zeta_{1 c}, x_{\mathrm{bl}}$, $\dot{x}_{\mathrm{bl}}, \alpha_{k}$, and $\alpha_{c}$ for the nonlinear model, for each test. A set of parameters was identified for each of the linear and nonlinear models that had the least RSS error. These parameters are $m_{c}$ $=60 \%$ of the dummy mass, $f_{c}=70 \mathrm{~Hz}$, and $\zeta_{c}=25 \%$ for the linear child model and $m_{1 c}=60 \%$ of the dummy mass, $f_{1 c}=$ $70 \mathrm{~Hz}, \zeta_{1 c}=25 \%, x_{\mathrm{bl}}=0.5 x_{\text {max }}, \dot{x}_{\mathrm{bl}}=0.5 \dot{x}_{\text {max }}, \alpha_{k}=1.1$, and $\alpha_{c}$ $=0.5$ for the bilinear child model.

These parameters are then used in the contact model to estimate the impact force time history for tests T01, T03, T04, and T05. Figure 5 compares the analytical (both linear and nonlinear contact models) and experimental impact force signals at force plate DoF for tests T02 and T04.

The estimated peak impact forces are compared in Figure 6 for all tests.

As can be seen in Figure 6, the magnitude of the force transmitted to the human body during impact (child forces) is considerably different from the total force measured by the force plate (total forces). The child force here is defined as the force between the human and the force plate DoFs (Section 3).

Both linear and nonlinear models estimated the peak impact force with a reasonable accuracy of 5\%-13\% and $2 \%-$ $10 \%$, respectively. However, the nonlinear model consistently estimated the behavior of the dynamic system and the peak impact forces with higher fidelity (Figure 5).

Figure 7 compares the impact force experienced by the child in tests T02 and T04 with and without taking into account the interaction with the force plate.

The noninteractive impact force experienced by the child was estimated using an SDOF model of the child attached to a rigid (not vibrating) ground and excited with an initial velocity, representing its velocity at the beginning of the impact. To be able to compare the results of the interactive and noninteractive models, the same dynamic parameters of the child SDOF model identified for the interactive model were used in noninteractive model. The magnitudes of the peak impact force experienced by the child with and without taking into account the interaction effects are compared in Figure 6 for all tests. As can be seen in this figure, between $3 \%-7 \%$ difference can be seen in the peak impact forces of the interactive and noninteractive models.

Figure 8 shows the simulated displacement of the child and the force plate DoFs during the impact experienced during tests T02 and T04.

The child and force plate DoFs are in contact during the compression ((A)-(B)) and restitution ((B)-(C)) phases. During the compression phase, the child body decelerates 

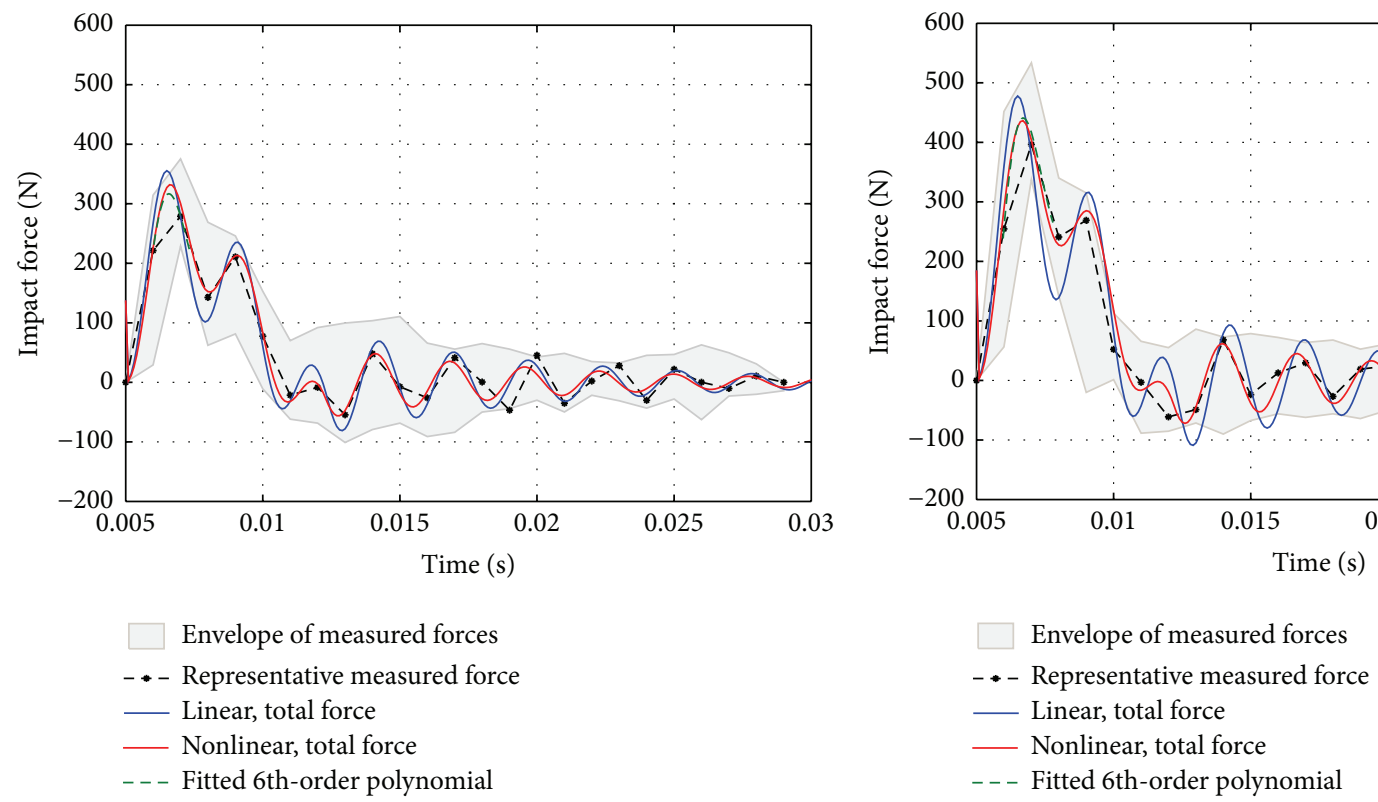

(a)

(b)

FIGURE 5: Comparison of the impact force time histories for the tests T02 (a) and T04 (b).

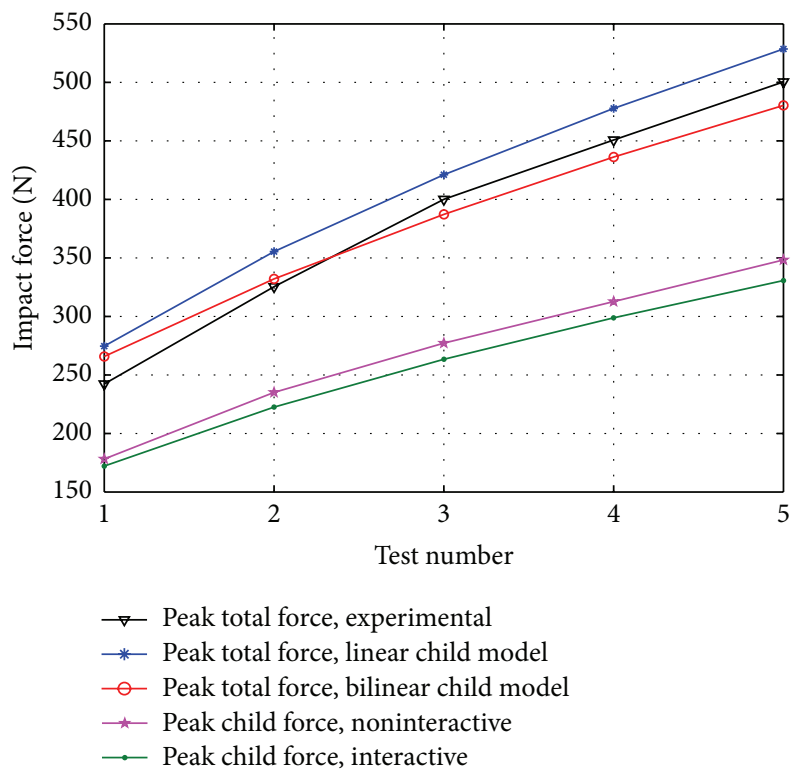

FIGURE 6: Comparison of the measured and estimated peak impact forces.

$\left(\ddot{x}_{c}(t)\right)$ and the force plate top plate (sitting on top of the sensors) accelerates $\left(\ddot{x}_{f}(t)\right)$. The force value that force plate sensors show is the total force resulting from both the child body $\left(m_{c}\right)$ and the top plate $\left(m_{f}\right)$ masses which is $m_{c} \ddot{x}_{c}(t)+$ $m_{f} \ddot{x}_{f}(t)$, whereas the force experienced by the child in this phase is only $m_{c} \ddot{x}_{c}(t)$. At point (C), the child detaches from the force plate and starts flying up in the air, when the only force applied to it is gravity. Between (A) and (C), at least three mechanisms affect the force experienced by the child DoF.
(1) The first mechanism is related to the exchange of momentum between the masses of the two impacting bodies. According to Newton's third law of motion and the principle of conservation of linear momentum, the momentum of the impacting bodies before (1) and after (2) and the collision are equal, assuming zero energy dissipation:

$$
m_{c} \dot{x}_{c, 1}(t)+m_{f} \dot{x}_{f, 1}(t)=m_{c} \dot{x}_{c, 2}(t)+m_{f} \dot{x}_{f, 2}(t) .
$$

According to this principle, part of the momentum of the child body before impact is transferred to the force plate top plate mass during impact and therefore the momentum of child body decreases compared to impacting a solid object. Knowing that changes in the momentum of an object $(m \cdot \Delta v)$ is equal to the impulse $(F \cdot \Delta t)$ experienced by that object,

$$
F \cdot \Delta t=m \cdot \Delta v
$$

it can be concluded that the child body experiences lower magnitude of force when impacting force plate compared to the solid object. In this analogy $\Delta t$ is assumed to be the same for both scenarios.

(2) The second mechanism is predominantly related to the stiffness of the impacting object. As force plate has less stiffness compared to a rigid object, it gives more time to the child body to decelerate during impact. This means that, for the same $\Delta v$ in (9), $\Delta t$ has larger magnitudes and therefore the peak impact force $F$ is lower compared to the case of impacting a rigid object.

(3) The third mechanism is related to the dissipation of the energy by the damping of the force plate. The energy transmitted to the force plate top plate during impact is dissipated by its damping while the top plate oscillates. 


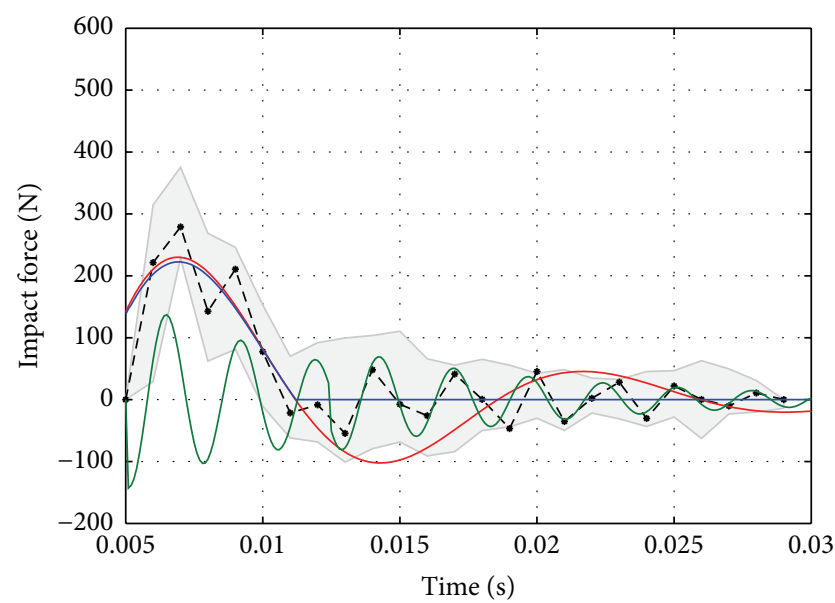

Envelope of measured forces

- - Representative measured force

- Noninteractive SDOF model

- Interactive model, child force

_ Interactive model, force plate force

(a)

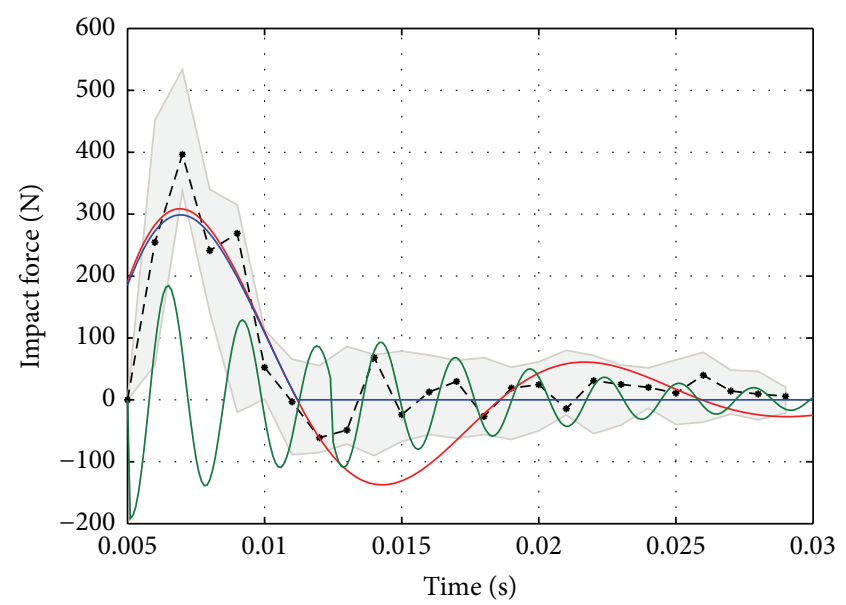

$\square$ Envelope of measured forces

- - Representative measured force

- Noninteractive SDOF model

— Interactive model, child force

_ Interactive model, force plate force

(b)

FiguRE 7: Comparison of the impact force experienced by a child, with and without taking into account the interaction with the force plate for tests T02 (a) and T04 (b).

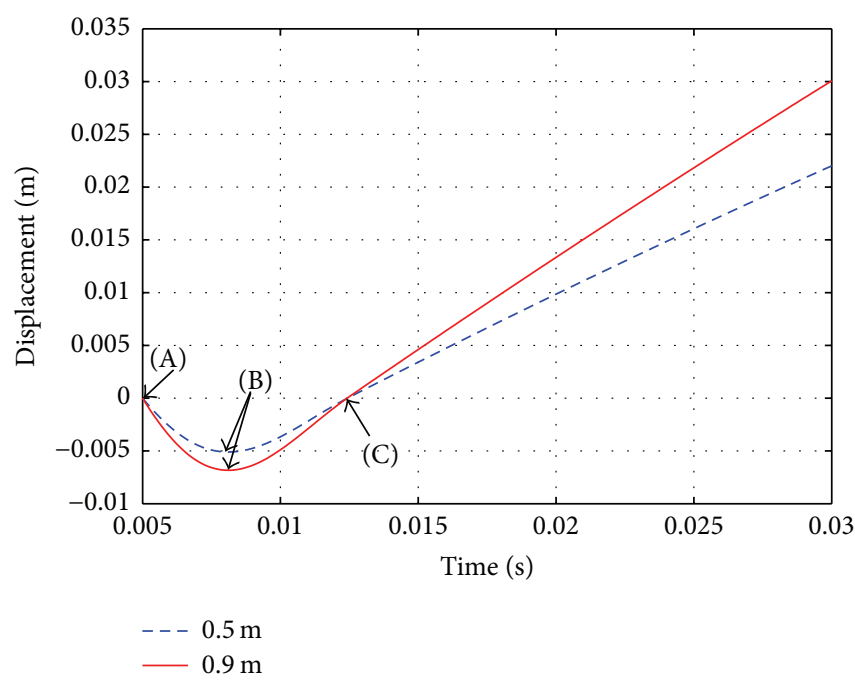

(a)

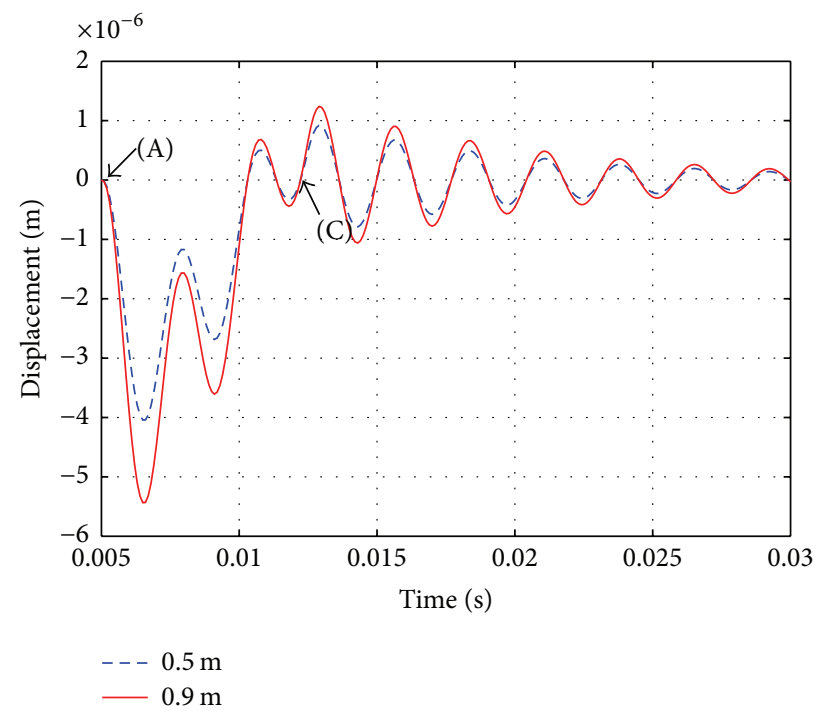

(b)

FIgURE 8: Simulated displacement of the child (a) and force plate (b) DoFs during impact for $0.5 \mathrm{~m}$ (T02) and $0.9 \mathrm{~m}$ (T04) fall heights.

\section{Fall on Floor Structures}

A parametric analysis was carried out to study the range of error in the peak impact force experienced by a falling human, if the dynamics of the floor structure are not taken into account. The 2-DoF human-structure linear model described in Section 3 was used to estimate the peak impact force $F_{\text {max int }}$ experienced by a falling human, when taking into account the interaction effects. This force is analogous to the impact force experienced by the child when falling on the force plate as described in Section 3. The noninteractive peak impact force $F_{\text {max,non int }}$ was estimated using an SDOF model of the human attached to a rigid (not vibrating) ground and excited with an initial velocity, representing its velocity at the beginning of the impact. In each simulation, two identical sets of human parameters $\left(m_{h}, f_{h}\right.$, and $\left.\zeta_{h}\right)$ were used in both models and the interactive and noninteractive peak impact forces were calculated. These force magnitudes were then used in the following formula to calculate the impact force 


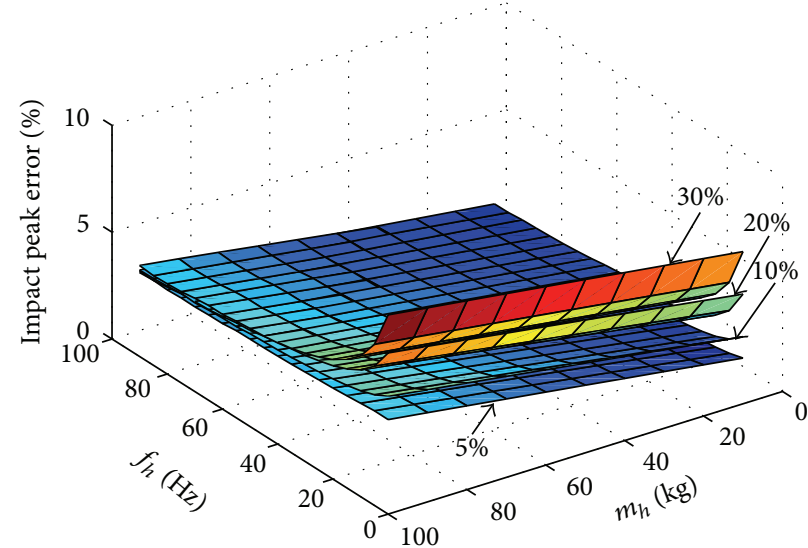

(a) $\zeta_{h}=5 \%, 10 \%, 20 \%$, and $30 \% ; m_{s}=3500 \mathrm{~kg} ; f_{s}=10 \mathrm{~Hz} ; \zeta_{s}=1 \%$

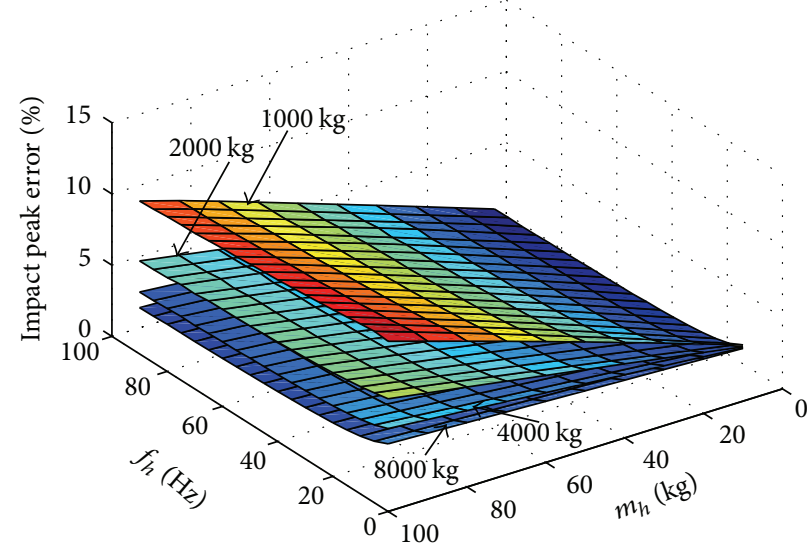

(c) $m_{s}=1000,2000,4000$, and $8000 \mathrm{~kg} ; \zeta_{h}=10 \% ; f_{s}=10 \mathrm{~Hz} ; \zeta_{s}=1 \%$

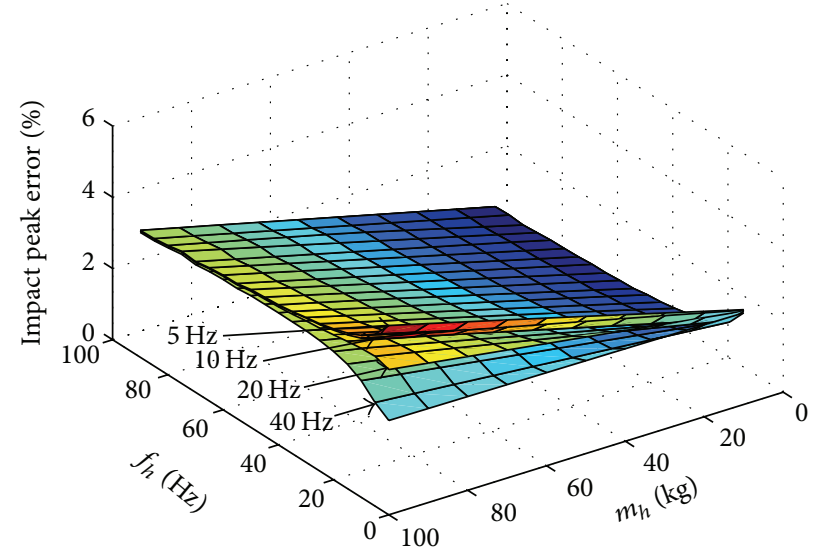

(e) $f_{s}=5 \mathrm{~Hz}, 10 \mathrm{~Hz}, 20 \mathrm{~Hz}$, and $40 \mathrm{~Hz} ; \zeta_{h}=10 \% ; m_{s}=3500 \mathrm{~kg} ; \zeta_{s}=1 \%$

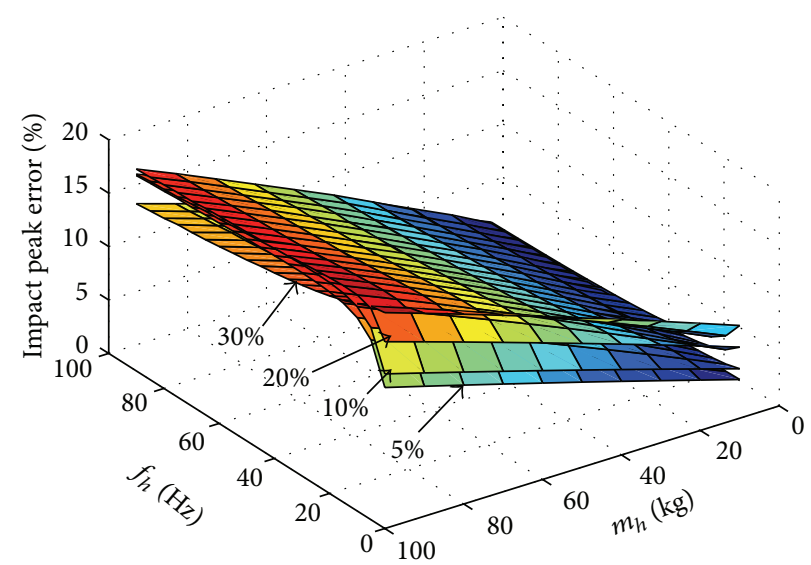

(b) $\zeta_{h}=5 \%, 10 \%, 20 \%$, and $30 \% ; m_{s}=500 \mathrm{~kg} ; f_{s}=20 \mathrm{~Hz} ; \zeta_{s}=1 \%$

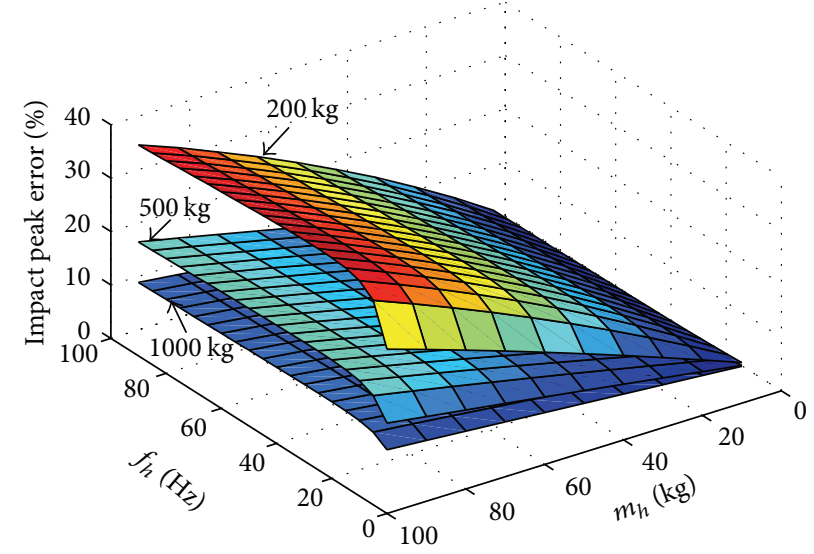

(d) $m_{s}=100,200,500$, and $1000 \mathrm{~kg} ; \zeta_{h}=10 \% ; f_{s}=20 \mathrm{~Hz} ; \zeta_{s}=1 \%$

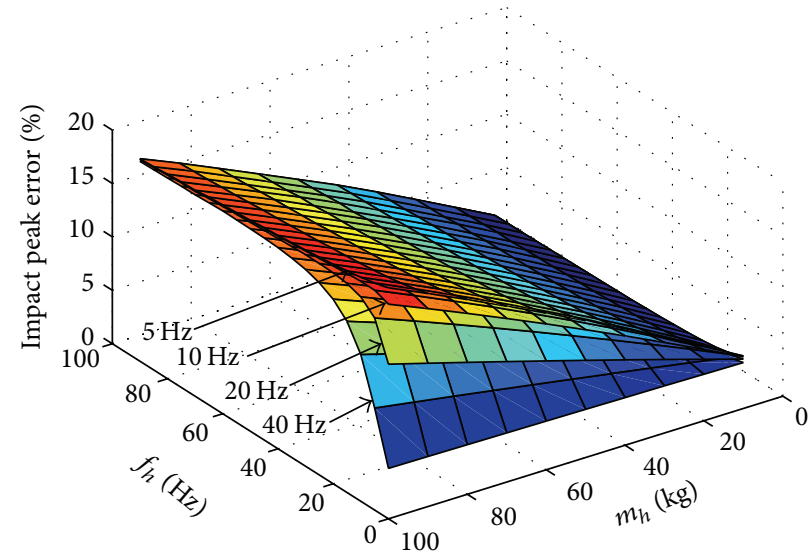

(f) $f_{s}=5 \mathrm{~Hz}, 10 \mathrm{~Hz}, 20 \mathrm{~Hz}$, and $40 \mathrm{~Hz} ; \zeta_{h}=10 \% ; m_{s}=500 \mathrm{~kg} ; \zeta_{s}=1 \%$

FIGURE 9: Effects of taking into account the floor dynamics on the peak impact force experienced by a human body: a typical building floor ((a), (c), and (e)) and a raised floor ((b), (d), and (f)).

peak error (IPE) percentage associated with neglecting the floor dynamics:

$$
\mathrm{IPE}=\left[\frac{\left(F_{\text {max, non int }}-F_{\text {max,int }}\right)}{F_{\text {max,non int }}}\right] \times 100 .
$$

All simulations were carried out for an initial falling height of $0.5 \mathrm{~m}$. The human model parameters were varied within reasonably wide ranges of $3 \mathrm{~kg}<m_{h}<100 \mathrm{~kg}$ (10 kg interval), $5 \mathrm{~Hz}<f_{h}<100 \mathrm{~Hz}\left(5 \mathrm{~Hz}\right.$ interval), and $5 \%<\zeta_{h}<30 \%$ to compensate for their variability and uncertainty. A typical lightweight building floor with $m_{s}=3500 \mathrm{~kg}, f_{s}=10 \mathrm{~Hz}$, and $\zeta_{s}=1 \%$ and a raised floor with $m_{s}=500 \mathrm{~kg}, f_{s}=20 \mathrm{~Hz}$, and $\zeta_{s}=1 \%$ were considered in the first set of analyses [53-56]. Figures 9(a) and 9(b) show the expected IPE for the selected building and raised floors for $\zeta_{h}=5 \%, 10 \%, 20 \%$, and $30 \%$. 
In general, when $m_{h}$ increases, the IPE increases. This is, according to contact mechanics, because when $m_{h}$ increases, it transfers more kinetic energy to the structure DoF during impact and, therefore, remains with less energy. However, IPE does not show significant sensitivity to $\zeta_{h}$. IPE is more sensitive to $f_{h}$ when $5 \mathrm{~Hz}<f_{h}<20 \mathrm{~Hz}$ and in general increases as $\zeta_{h}$ increases. Up to $8 \%$ and $18 \%$ overestimation of peak impact force is expected within this $f_{h}$ range for the selected building floor and raised floor systems, respectively.

In the next set of simulations, the mass of the building floor and the raised floor SDOF models varied between $1,000 \mathrm{~kg}<m_{s}<8,000 \mathrm{~kg}$ (Figure 9(c)) and $100 \mathrm{~kg}<m_{s}<$ $1000 \mathrm{~kg}$ (Figure $9(\mathrm{~d})$ ), respectively. $\zeta_{h}$ was taken equal to $10 \%$ in these simulations. Both figures show the considerable sensitivity of the IPE (up to $12 \%$ and $37 \%$ error for building and raised floor systems, resp.) to the ratio of the mass of the floor structure to the human model mass. The lower this ratio is (higher human mass and lower structure mass) the more prominent the contribution of the floor dynamics in the impact force experienced by the falling human is.

In the last set of simulations, the natural frequency of the floor structure varied between $5 \mathrm{~Hz}<f_{s}<40 \mathrm{~Hz}$ (Figures 9(e) and 9(f)). Similar to the effects of $\zeta_{h}$ (Figures 9(a) and 9(b)), IPE is more sensitive to $f_{s}$ when $5 \mathrm{~Hz}<f_{h}<20 \mathrm{~Hz}$ and generally increases as $f_{s}$ decreases.

In general, as expected, the effects of floor dynamics are more prominent when the structure is lightweight and has lower frequency. The effects of structural natural frequency are more visible when the falling human is characterized with a low frequency and high mass model.

\section{Conclusions}

The dynamic interaction of a falling human body with a contacting object was studied in this paper, with particular focus on two important contacting bodies: (1) a grounded force plate as a standard tool for fall force measurement in a laboratory environment and (2) lightweight building floors and raised floors in indoor real-life falls. Two different human models were compared: a linear model with constant parameters and a nonlinear model, the stiffness and damping of which were bilinear and were displacement and velocity dependent, respectively. The following was found.

(i) The significant tension forces observed in the measured impact force using force plate suggest that the interaction of the falling human body and force plate in the laboratory measurement can be considerable and therefore need to be considered in contact models.

(ii) Both the interactive linear and nonlinear child-force plate contact models were able to successfully simulate the dynamics of the impact. They estimated the peak total impact force with errors of $5 \%-13 \%$ and $2 \%-10 \%$, respectively.

(iii) The nonlinear model consistently estimated the behavior of the dynamic system and the peak impact forces with higher accuracy (on average 18\% less error than the linear counterpart). (iv) Results of the parametric study carried out on a range of lightweight floors and raised floors showed that ignoring the dynamics of a lightweight floor in the contact model can result in up to $38 \%$ overestimation of the peak force experienced by a falling human. This shows that, for real-world indoor falls, depending on the dynamic properties of the floor/raised floor, there can be a significant interaction between falling human and structure. Therefore, the dynamics of the floor structure need to be considered in the contact model.

(v) The interaction effects are more prominent when the structure is more lightweight and has lower natural frequency. The effect of structural natural frequency is more visible when the falling human is characterized by a low natural frequency and high mass.

The methodology suggested in this study can be adapted for the simulation of different impact/fall scenarios. It provides extensive flexibility to simulate multibody contacts, human reflexes and reactions, and nonlinear behavior of the contacting bodies. Friction modelling and the motion in the tangential direction were not considered in this study, but future studies might investigate their effects on the impact dynamics and explore their role, for instance, in push falls.

The experiments carried out in this research were done on a scaled dummy, using nonbiofidelic joint and tissue mechanics. More detailed experiments on real-world instrumented floor structures and raised floors using a more realistic human physical representation (dummies with higher biofidelity, cadaver, etc.) can extend the findings of this research for different fall mechanisms, postures, and structures.

\section{Competing Interests}

The authors declare that there are no competing interests regarding the publication of this paper.

\section{Acknowledgments}

The authors acknowledge the financial support which came from the UK Engineering and Physical Sciences Research Council (EPSRC) for Platform Grant EP/G061130/2 (Dynamic Performance of Large Civil Engineering Structures: An Integrated Approach to Management, Design, and Assessment), EP/K03877X/1 (Modelling Complex and Partially Identified Engineering Problems: Application to the Individualised Multi-Scale Simulation of the Musculoskeletal System), and EP/J013714/1 (Human-Machine Co-operation in Robotics and Autonomous Systems, Great Technologies Capital Call, Robotics and Autonomous Systems).

\section{References}

[1] G. Gilardi and I. Sharf, "Literature survey of contact dynamics modelling," Mechanism and Machine Theory, vol. 37, no. 10, pp. 1213-1239, 2002.

[2] J. Mizrahi and Z. Susak, "Analysis of parameters affecting impact force attenuation during landing in human vertical free fall," Engineering in Medicine, vol. 11, no. 3, pp. 141-147, 1982. 
[3] J. Mizrahi and Z. Susak, "In-vivo elastic and damping response of the human leg to impact forces," Journal of Biomechanical Engineering, vol. 104, no. 1, pp. 63-65, 1982.

[4] H. Nevzat Özgüven and N. Berme, "An experimental and analytical study of impact forces during human jumping," Journal of Biomechanics, vol. 21, no. 12, pp. 1061-1066, 1988.

[5] J. Chiu and S. N. Robinovitch, "Prediction of upper extremity impact forces during falls on the outstretched hand," Journal of Biomechanics, vol. 31, no. 12, pp. 1169-1176, 1998.

[6] D. M. Andrews and J. J. Dowling, "Mechanical modeling of tibial axial accelerations following impulsive heel impact," Journal of Applied Biomechanics, vol. 16, no. 3, pp. 276-288, 2000.

[7] M. Nasiri Sarvi, L. Luo, P. Sun, and J. Ouyang, "Experimental validation of subject-specific dynamics model for predicting impact force in sideways fall," Journal of Biomedical Science and Engineering, vol. 7, pp. 405-418, 2014.

[8] L. H. Light and G. McLellan, "Skeletal transients associated with heel strike," Journal of Physiology, vol. 272, no. 1, pp. 9P-10P, 1977.

[9] L. H. Light, G. E. McLellan, and L. Klenerman, "Skeletal transients on heel strike in normal walking with different footwear," Journal of Biomechanics, vol. 13, no. 6, pp. 477-480, 1980.

[10] J. Wosk and A. Voloshin, "Wave attenuation in skeletons of young healthy persons," Journal of Biomechanics, vol. 14, no. 4, pp. 261-267, 1981.

[11] M. L. Chu, S. Yazdani-Ardakani, I. A. Gradisar, and M. J. Askew, "An in vitro simulation study of impulsive force transmission along the lower skeletal extremity," Journal of Biomechanics, vol. 19, no. 12, pp. 979-987, 1986.

[12] M. H. Popo, D. G. Wilder, L. Jorneus, H. Broman, M. Svensson, and G. Andersson, "The response of the seated human to sinusoidal vibration and impact," Journal of Biomechanical Engineering, vol. 109, no. 4, pp. 279-284, 1987.

[13] S. M. McGill, A. Thorstensson, and R. W. Norman, "Non-rigid response of the trunk to dynamic axial loading: an evaluation of current modelling assumptions," Clinical Biomechanics, vol. 4, no. 1, pp. 45-50, 1989.

[14] W. Kim, A. S. Voloshin, S. H. Johnson, and A. Simkin, "Measurement of the impulsive bone motion by skin-mounted accelerometers," Journal of Biomechanical Engineering, vol. 115, no. 1, pp. 47-52, 1993.

[15] M. A. Lafortune, M. J. Lake, and E. M. Hennig, "Differential shock transmission response of the human body to impact severity and lower limb posture," Journal of Biomechanics, vol. 29, no. 12, pp. 1531-1537, 1996.

[16] M. H. Pope, M. Magnusson, and T. Hansson, "The upper extremity attenuates intermediate frequency vibrations," Journal of Biomechanics, vol. 30, no. 2, pp. 103-108, 1997.

[17] E. Shahabpoor, A. Pavic, and V. Racic, "Identification of massspring-damper model of walking humans," Structures, vol. 5, pp. 233-246, 2016.

[18] W. J. Choi, J. A. Hoffer, and S. N. Robinovitch, "Effect of hip protectors, falling angle and body mass index on pressure distribution over the hip during simulated falls," Clinical Biomechanics, vol. 25, no. 1, pp. 63-69, 2010.

[19] T. A. Burkhart and D. M. Andrews, "Kinematics, kinetics and muscle activation patterns of the upper extremity during simulated forward falls," Journal of Electromyography and Kinesiology, vol. 23, no. 3, pp. 688-695, 2013.
[20] S. Bhan, I. C. Levine, and A. C. Laing, "Energy absorption during impact on the proximal femur is affected by body mass index and flooring surface," Journal of Biomechanics, vol. 47, no. 10, pp. 2391-2397, 2014.

[21] M. Shea, W. T. Edwards, A. A. White, and W. C. Hayes, "Variations of stiffness and strength along the human cervical spine," Journal of Biomechanics, vol. 24, no. 2, pp. 95-107, 1991.

[22] N. Yoganandan, F. A. Pintar, A. Sances Jr. et al., "Biomechanics of skull fracture," Journal of Neurotrauma, vol. 12, no. 4, pp. 659$668,1995$.

[23] Y. Zheng and A. F. T. Mak, "Effective elastic properties for lower limb soft tissues from manual indentation experiment," IEEE Transactions on Rehabilitation Engineering, vol. 7, no. 3, pp. 257267, 1999.

[24] M. B. Silver-Thom, "In vivo indentation of lower extremity limb soft tissues," IEEE Transactions on Rehabilitation Engineering, vol. 7, no. 3, pp. 268-277, 1999.

[25] M. T. Prange, J. F. Luck, A. Dibb, C. A. Van Ee, R. W. Nightingale, and B. S. Myers, "Mechanical properties and anthropometry of the human infant head," Stapp Car Crash Journal, vol. 48, pp. 279-299, 2004.

[26] A. Loyd, Studies of the Human Head from Neonate to Adult: An Inertial, Geometrical and Structural Analysis with Comparisons to the ATD Head, Duke University, 2011.

[27] A. C. Duhaime, A. J. Alario, W. J. Lewander et al., "Head injury in very young children: mechanisms, injury types, and ophthalmologic findings in 100 hospitalized patients younger than 2 years of age," Pediatrics, vol. 90, no. 2, pp. 179-185, 1992.

[28] J. M. Leventhal, S. A. Thomas, N. S. Rosenfield, and R. I. Markowitz, "Fractures in young children: distinguishing child abuse from unintentional injuries," American Journal of Diseases of Children, vol. 147, no. 1, pp. 87-92, 1993.

[29] R. T. Strait, R. M. Siegel, and R. A. Shapiro, "Humeral fractures without obvious etiologies in children less than 3 years of age: when is it abuse?" Pediatrics, vol. 96, no. 4, pp. 667-671, 1995.

[30] S. A. Scherl, L. Miller, N. Lively, S. Russinoff, C. M. Sullivan, and P. Tornetta, "Accidental and non-accidental femur fractures in children," Clinical Orthopaedics, vol. 376, pp. 96-105, 2000.

[31] M. T. Prange, B. Coats, A.-C. Duhaime, and S. S. Margulies, "Anthropomorphic simulations of falls, shakes, and inflicted impacts in infants," Journal of Neurosurgery, vol. 99, no. 1, pp. 143-150, 2003.

[32] G. E. Bertocci, M. C. Pierce, E. Deemer, F. Aguel, J. E. Janosky, and E. Vogeley, "Using test dummy experiments to investigate pediatric injury risk in simulated short-distance falls," Archives of Pediatrics and Adolescent Medicine, vol. 157, no. 5, pp. 480486, 2003.

[33] G. E. Bertocci, M. C. Pierce, E. Deemer, F. Aguel, J. E. Janosky, and E. Vogeley, "Influence of fall height and impact surface on biomechanics of feet-first free falls in children," Injury, vol. 35, no. 4, pp. 417-424, 2004.

[34] B. Coats and S. S. Margulies, "Potential for head injuries in infants from low-height falls: laboratory investigation," Journal of Neurosurgery: Pediatrics, vol. 2, no. 5, pp. 321-330, 2008.

[35] A. K. Thompson, G. Bertocci, and M. C. Pierce, "Assessment of head injury risk associated with feet-first free falls in 12-monthold children using an anthropomorphic test device," Journal of Trauma and Acute Care Surgery, vol. 66, no. 4, pp. 1019-1029, 2009.

[36] N. G. Ibrahim and S. S. Margulies, "Biomechanics of the toddler head during low-height falls: an anthropomorphic dummy 
analysis-laboratory investigation," Journal of Neurosurgery: Pediatrics, vol. 6, no. 1, pp. 57-68, 2010.

[37] A. K. Thompson, G. Bertocci, W. Rice, and M. C. Pierce, "Pediatric short-distance household falls: biomechanics and associated injury severity," Accident Analysis \& Prevention, vol. 43, no. 1, pp. 143-150, 2011.

[38] A. Thompson and G. Bertocci, "Pediatric bed fall computer simulation model: parametric sensitivity analysis," Medical Engineering and Physics, vol. 36, no. 1, pp. 110-118, 2014.

[39] AMTI (Advanced Mechanical Technology Inc), "BP4006001000 Specifications," 2016, http://www.amti.biz/AMTIpibrowser.aspx.

[40] VICON Motion Systems, 2016, http://www.vicon.com/products/camera-systems/vantage.

[41] W. Goldsmith, Impact: the Theory and Physical Behaviour of Colliding Solids, Edward Arnold Publishers, London, UK, 1960.

[42] P. Barkan, Impact Design. Mechanical Design and Systems Handbook, vol. 31, McGraw-Hill, New York, NY, USA, 1974.

[43] R. M. Brach, Mechanical Impact Dynamics: Rigid Body Collisions, John Wiley and Sons, New York, NY, USA, 1991.

[44] Y. Wang and M. T. Mason, "Two-dimensional rigid-body collisions with friction," Journal of Applied Mechanics, vol. 59, no. 3, pp. 635-642, 1992.

[45] R. G. Snyder, "Human tolerances to extreme impacts in freefall," Aerospace Medical Association Journal, vol. 34, pp. 85-90, 1963.

[46] C. Z. Cory, M. D. Jones, D. S. James, S. Leadbeatter, and L. D. M. Nokes, "The potential and limitations of utilising head impact injury models to assess the likelihood of significant head injury in infants after a fall," Forensic Science International, vol. 123, no. 2-3, pp. 89-106, 2001.

[47] D. Mohan, B. M. Bowman, R. G. Snyder, and D. R. Foust, "A biomechanical analysis of head impact injuries to children," Journal of Biomechanical Engineering, vol. 101, no. 4, pp. 250260, 1979.

[48] A. M. Loyd, R. W. Nightingale, J. F. Luck et al., "The compressive stiffness of human pediatric heads," Journal of Biomechanics, vol. 48, no. 14, pp. 3766-3775, 2015.

[49] L. Gustafsson and M. Sternad, "Consistent micro, macro and state-based population modelling," Mathematical Biosciences, vol. 225, no. 2, pp. 94-107, 2010.

[50] M. W. Macy and R. Willer, "From factors to actors: computational sociology and agent-based modeling," Annual Review of Sociology, vol. 28, pp. 143-166, 2002.

[51] N. R. Jennings, K. Sycara, and M. Wooldridge, "A roadmap of agent research and development," Autonomous Agents and Multi-Agent Systems, vol. 1, no. 1, pp. 7-38, 1998.

[52] A. K. Chopra, Dynamics of Structures: Theory and Applications to Earthquake Engineering, Pearson Prentice Hall, Upper Saddle River, NJ, USA, 3rd edition, 2007.

[53] A. Pavic, P. Reynolds, P. Waldron, and K. J. Bennett, "Critical review of guidelines for checking vibration serviceability of post-tensioned concrete floors," Cement and Concrete Composites, vol. 23, no. 1, pp. 21-31, 2001.

[54] A. Pavic and P. Reynolds, "Appendix C: dynamic testing of building floors," in Design of Floors for Vibration, A. L. Smith, S. J. Hicks, and P. J. Devine, Eds., pp. 84-96, 2007.

[55] J. Weckendorf, B. Zhang, A. Kermani, D. Reid, and P. Andersen, "Damping characteristics of timber flooring systems with respect to low-frequency vibration modes," in Proceedings of the 10th World Conference on Timber Engineering, pp. 2205-2212, Miyazaki, June 2008.

[56] K. Jarnerö, A. Brandt, and A. Olsson, "Vibration properties of a timber floor assessed in laboratory and during construction," Engineering Structures, vol. 82, no. 1, pp. 44-54, 2015. 


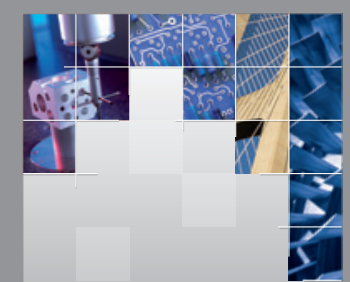

\section{Enfincering}
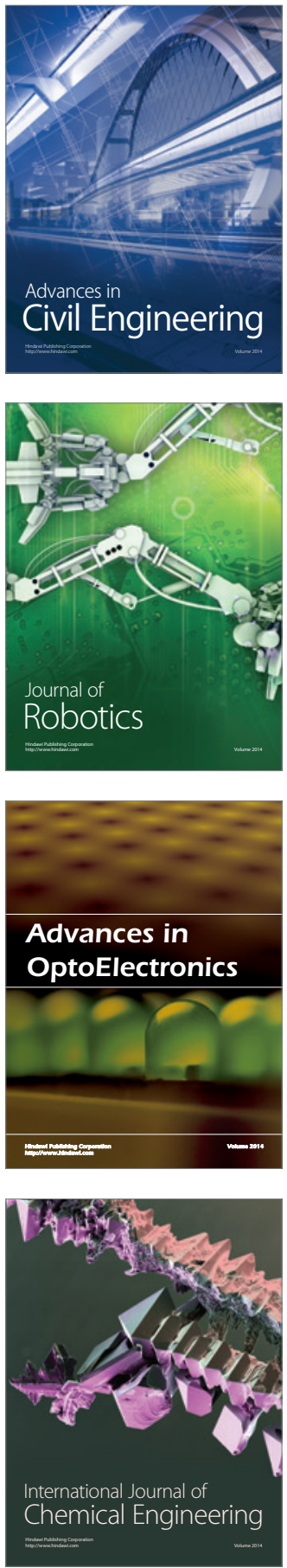

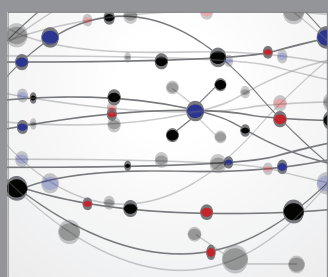

The Scientific World Journal

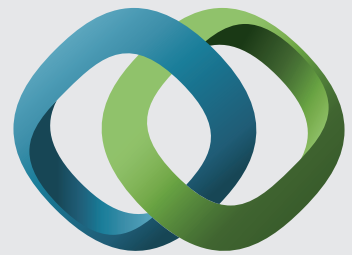

\section{Hindawi}

Submit your manuscripts at

http://www.hindawi.com
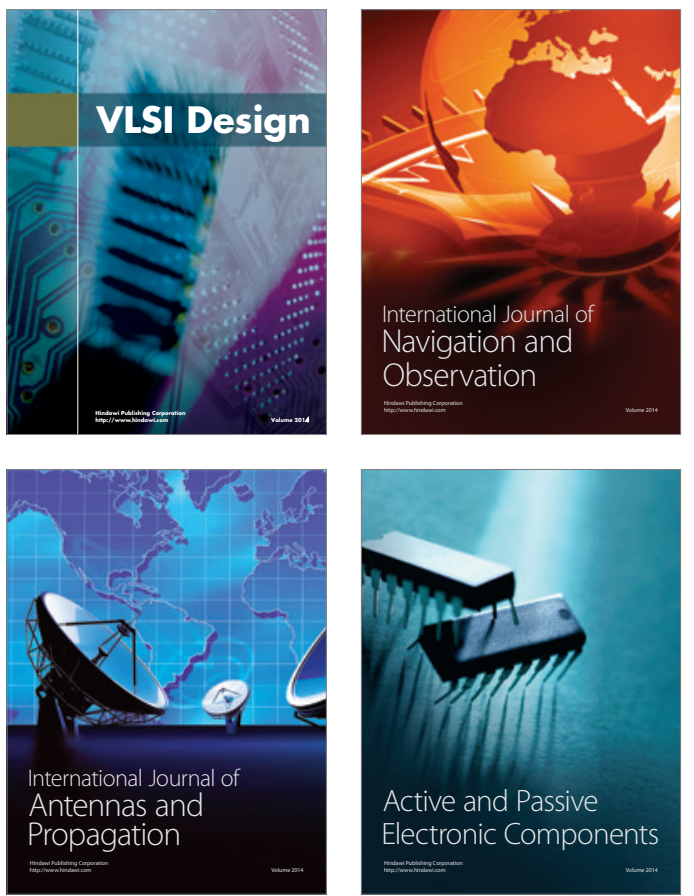
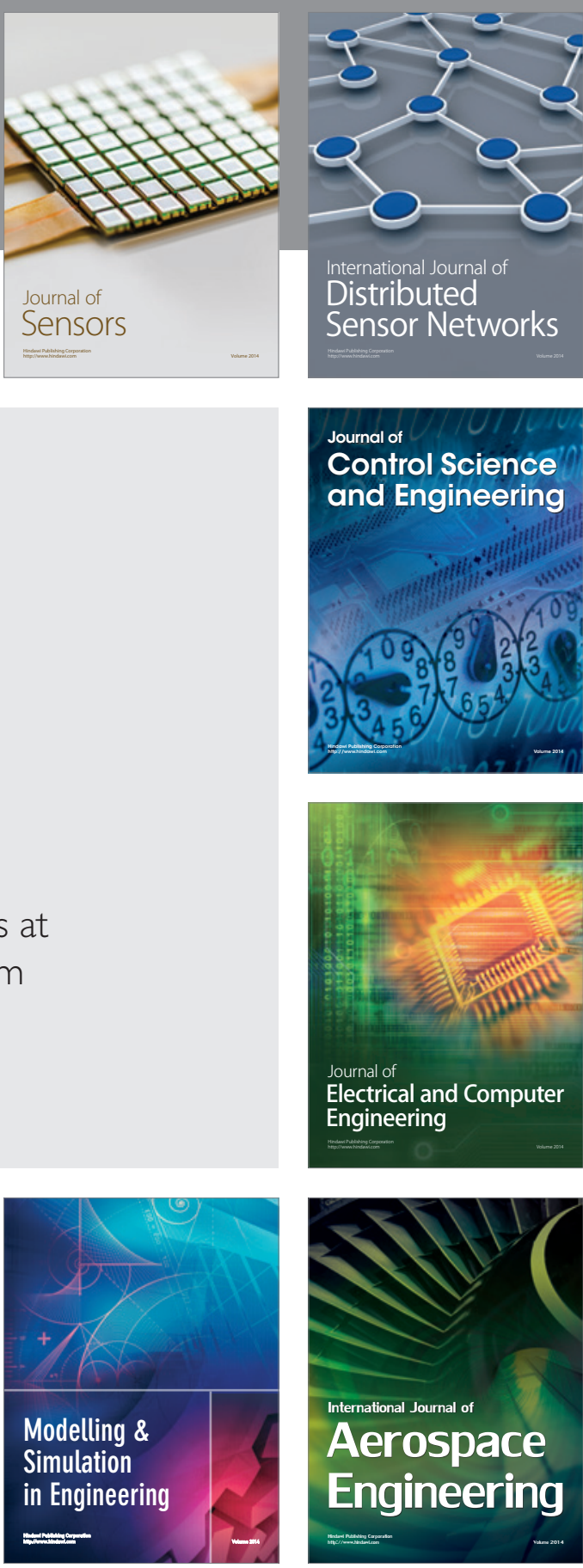

International Journal of

Distributed

Sensor Networks

Journal of

Control Science

and Engineering
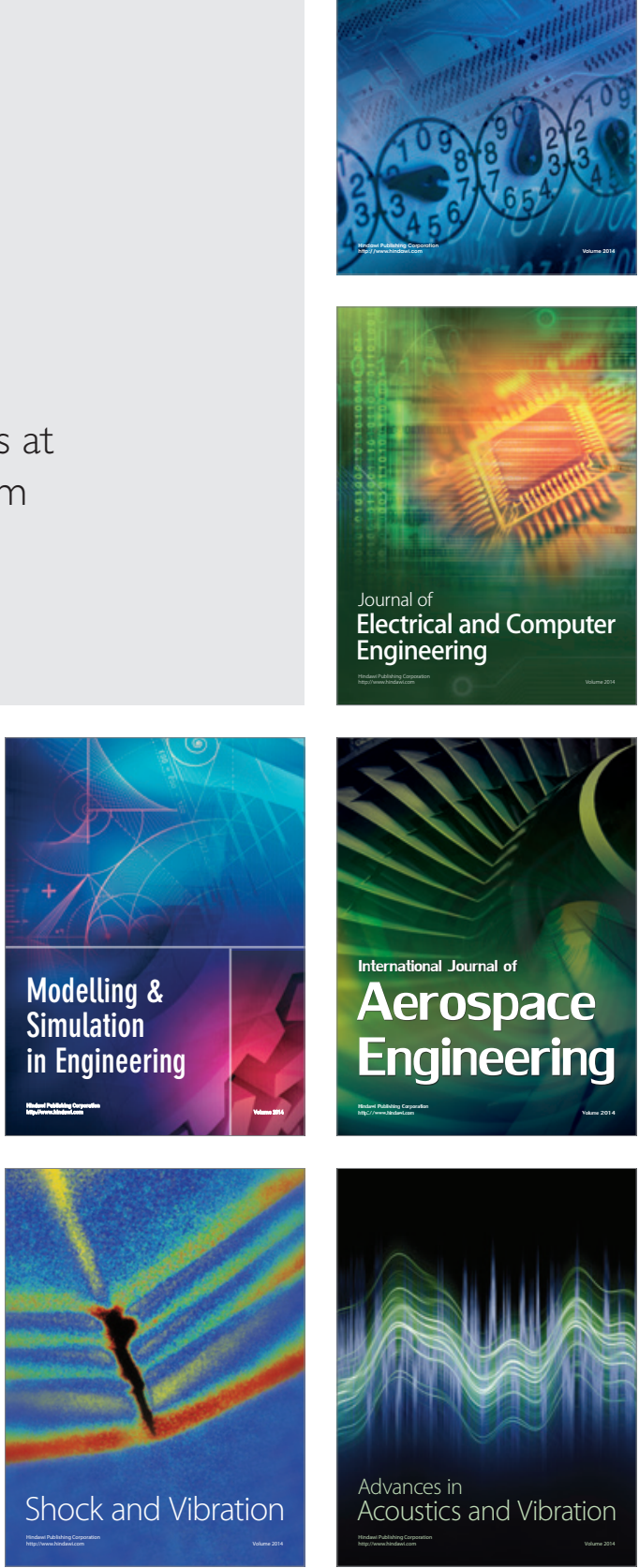